\title{
Fasceíte Necrotizante da Mama: Relato de Caso
}

\author{
Necrotizing Fasciitis of the Breast: Case Report
}

Marco Aurélio da Costa Silva, Jales Benevides Santana Filho

Ruffo de Freitas Júnior, Edgar Berquó Peleja

Rossana de Araújo Catão, Luiz Fernando Jubé Ribeiro

\begin{abstract}
RESUM0
É apresentado um caso de fasceite necrotizante, na mama, em uma paciente de 68 anos que foi submetida à excisão de um volumoso lipoma mamário e evoluiu com infecção local agressiva, apresentando necrose extensa do parênquima da mama e de suas fáscias, além da pele, quadro este que caracteriza as fasceites. O trabalho chama a atenção para a gravidade da entidade e a dificuldade diagnóstica, em razão do comprometimento cutâneo mais tardio e menos extenso; enfatiza-se a necessidade de afastar tal diagnóstico na vigência de infecções mamárias, assim como ter uma abordagem precoce e agressiva na presença de um quadro de fasceite necrotizante mamária.
\end{abstract}

PALAVRAS-CHAVE: Mama: Doença benigna. Cirurgia: Complicações. Infecção. Fasceíte necrotizante.

\section{Introdução}

A fasceíte necrotizante é uma entidade rara, de sinonímia ampla e definida como sendo um processo infeccioso grave representado por gangrena aguda do tecido subcutâneo e fáscias superficiais, com preservação parcial da pele suprajacente e da musculatura abaixo do processo. Geralmente é causada por sinergismo de bactérias de grande agressividade, incluindo a associação de estreptococos e anaeróbios, e associada com altas taxas de mortalidade em razão da liberação

Trabalho realizado no Serviço de Ginecologia e Mama e Comissão de Controle de Infecção Hospitalar do Hospital Araújo Jorge da Associação de Combate ao Câncer em Goiás.

Correspondência:

Ruffo de Freitas Júnior

Alameda das Rosas, 533, S. Oeste

74110-060 - Goiânia/GO

Fax: (062) 212-2049 de toxinas pelos patógenos na corrente sangüinea ${ }^{1,2,4}$. Geralmente ocorre em pacientes imunodeprimidos, alcoólatras e diabéticos, tendo seu início em foco cutâneo. Os casos pós-cirúrgicos são mais raros, sendo os locais mais comuns a parede abdominal, o períneo e as extremidades ${ }^{6}$.

Este relato tem o objetivo de descrever um caso de fasceíte necrotizante pós-operatória na mama ocorrido em nosso serviço. Chamamos a atenção para a dificuldade do diagnóstico precoce desta entidade e do seu tratamento, dificuldade esta que está presente também nos casos clássicos de fasceíte.

\section{Relato do caso}

MCF, 68 anos, sexo feminino, casada, natural e residente no estado de Goiás. Procurou o Serviço 
de Ginecologia e Mama do HAJ/ACCG, referindo tumoração na mama direita há vários meses, com crescimento lento e indolor.

Antecedentes: tabagista desde a adolescência. Negava doenças prévias. A única operação realizada havia sido a exérese de um nódulo mamário, na proximidade do atual. Menarca aos 16 anos, menopausa aos 40 anos. Gesta VI, Para V, Aborto I. Amamentou os cinco filhos (total 120 meses).

Ao exame físico notou-se à inspeção abaulamento no QSE da mama direita, onde à palpação havia nódulo de superfície regular e bocelada, de consistência macia, indolor, medindo aproximadamente $10 \mathrm{~cm} \times 8 \mathrm{~cm}$. Mama esquerda, axilas e fossa supraclaviculares sem alterações. $\mathrm{Na}$ parede do tórax, inferiormente à mama direita, havia outro nódulo de aproximadamente $6 \mathrm{~cm}$, com as mesmas características.

Com a hipótese diagnóstica de lipoma da mama e da parede do tórax, foram solicitados: mamografia, complementada com ultra-som de mama, biópsia por agulha (Biopty-cut) e punção aspirativa por agulha fina (PAAF), conforme a conduta do Serviço.

A mamografia mostrou extensa substituição adiposa, porém sem lesões identificáveis. A ultrasonografia revelou imagem nodular hipoecogênica, de contornos regulares, limites precisos, com conteúdo heterogêneo e sem sombra acústica posterior. A PAAF foi representada por aspirado contendo células adiposas maduras, sem outras particularidades, e ausência de células ductais. A biópsia histológica por agulha grossa revelou a presença de tecido fibroso frouxo, sem outras particularidades.

A paciente foi submetida à ressecção da lesão mamária, sob anestesia geral. A incisão foi feita sobre a lesão. Imediatamente antes da operação foi feita antibioticoterapia profilática com $1 \mathrm{~g}$ de cefazolina IV e degermação da pele com PVPI tópico a $1 \%$. Durante a operação não houve intercorrências.

Em virtude da extensão do descolamento mamário, foi deixado um dreno tubular fino de aspiração contínua, por $48 \mathrm{~h}$. A paciente teve alta hospitalar no mesmo dia da operação.

No quinto dia de pós-operatório, a paciente compareceu ao Setor de Emergência do HAJ, apresentando dor intensa no local operado, febre alta, astenia, anorexia e cefaléia contínua. Ao exame físico, detectou-se ferida operatória com extenso foco de abscesso e hiperemia, que se estendia até a região cervical homolateral.

Foi realizada drenagem cirúrgica imediata do abscesso, com saída de grande quantidade de secreção purulenta. Instituiu-se antibioticoterapia com cefadroxil $500 \mathrm{mg} \mathrm{12/12} \mathrm{h} \mathrm{VO.}$

No oitavo dia de pós-operatório a paciente retornou apresentando piora do estado geral. Observavam-se lesões cutâneas bolhosas e lesões violáceas escurecidas em toda a mama direita e parede anterior do tórax (Figura 1). O hemograma mostrava uma anemia importante, que foi corrigida com transfusão de concentrado de hemáceas.

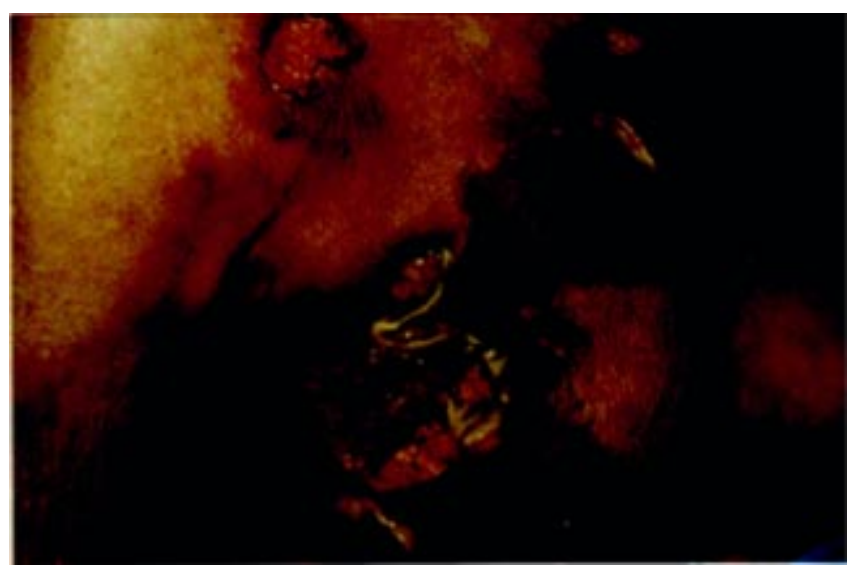

Figura 1 - Oitavo dia de pós-operatório: presença de lesões cutâneas bolhosas e lesões violáceas escurecidas em toda a mama direita e parede anterior do tórax.

Com a paciente internada, foi colhido material para cultura de ambas as lesões. Iniciou-se suporte hidroeletrolítico adequado. Procedeu-se à mudança da antibioticoterapia para vancomicina (visando estafilococos) e ceftazidima (visando principalmente pseudomonas), além de amicacina.

Não houve crescimento bacteriano nas culturas, de ambas as lesões, provavelmente pelo uso prévio do antibiótico. No $9^{\circ}$ dia de pós operatório, já havia melhora parcial do quadro geral, porém com o aparecimento de necrose dérmica na mama operada (Figura 2). A paciente foi submetida a debridamento cirúrgico de toda a área afetada, seguido de curativos com açúcar, com freqüência de quatro vezes ao dia.

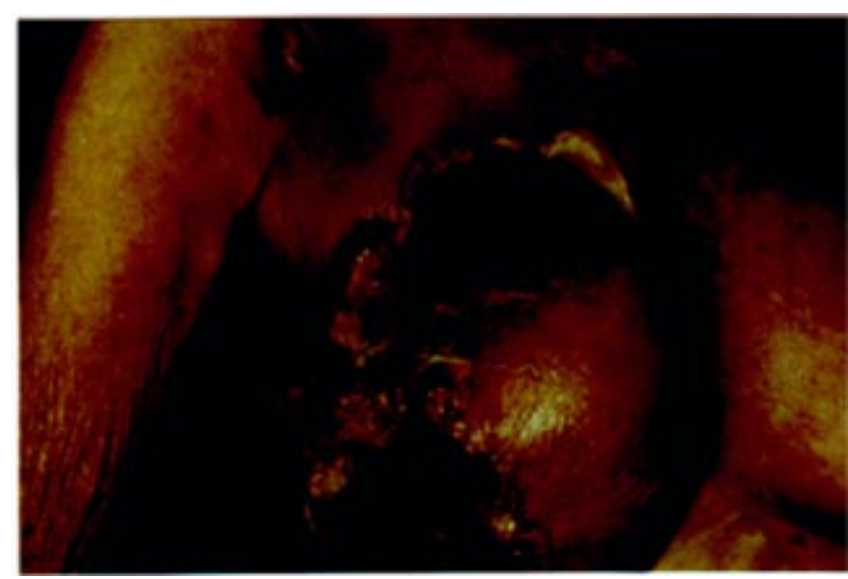

Figura 2 - Nono dia de pós-operatório: instalação de necrose dérmica na mama operada. 
Na evolução, observou-se diminuição da secreção e da fibrina, associada a processo de granulação progressivo (Figura 3). A antibioticoterapia foi mantida por 16 dias, sendo que a paciente obteve alta hospitalar ao seu término. Foi mantido seguimento ambulatorial, com curativos diários. No $55^{\circ} \mathrm{PO}$ houve cicatrização total da ferida.

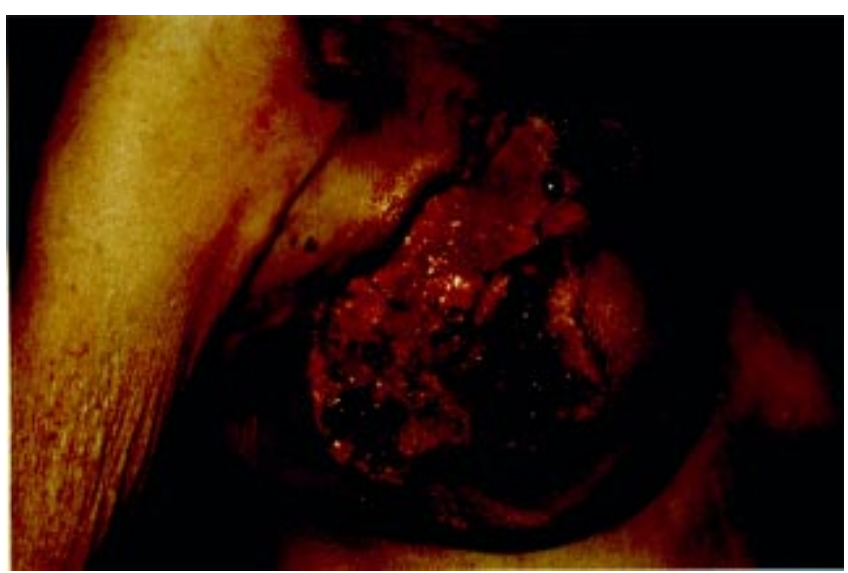

Figura 3 - Aspecto após o início de curativos, observando-se diminuição da secreção e da fibrina, associado a processo de granulação progressivo.

\section{Discussão}

A maior divulgação dos métodos de detecção do câncer de mama tem trazido um número crescente de mulheres aos consultórios especializados e, conseqüentemente, tem aumentado o número de procedimentos cirúrgicos. Das cirurgias mamárias, por serem procedimentos de superfície, espera-se uma pequena taxa de complicações.

Dentre as complicações os hematomas são os mais freqüentes, e para pequenos procedimentos, é esperada uma taxa de infecção ao redor de 2 a $8 \%$. Mesmo quando ocorrem, os processos inflamatórios e infecciosos pós-procedimentos cirúrgicos mamários costumam ser de pequena monta e de fácil resolução (pequenos abscessos que evoluem bem após simples drenagem $)^{3,5}$.

As infecções graves, por sua vez, são raras no tecido mamário e, quando ocorrem, geralmente estão relacionadas a cirurgias de grande porte, associadas com alguma doença de base, como: diabetes, uso de drogas, imunodepressão por quimioterapia, desnutrição, doença vascular periférica e obesidade ${ }^{6}$. No presente relato, verificase que a paciente apresentava alguns fatores de risco para infecção hospitalar (idade acima de 65 anos e obesidade) e, por este motivo foi utilizada a antibioticoprofilaxia.
Um fator que pode ser relacionado ao processo é o uso do dreno após a ressecção da lesão. No entanto, em um estudo randomizado prospectivo do nosso grupo, foi possível concluir que a drenagem não aumentou a taxa de infecção, além de ter possibilitado uma redução na taxa de hematomas ${ }^{3}$.

A necessidade de um bom resultado estético leva, em alguns casos, o mastologista a ser menos agressivo nas infecções e abscessos mamários do que seria com os mesmos em outras topografias. Notamos porém que, instalado um quadro de infecção grave, como a fasceíte necrotizante aqui relatada, a intervenção medicamentosa e cirúrgica deve ser tão precoce e agressiva quanto possível, pois o comprometimento menor e mais tardio da pele pode mascarar o diagnóstico, levando a uma maior perda tecidual e, portanto, piora do resultado estético, além do alto risco de óbito ${ }^{2}$.

Por fim, esse caso deve chamar a atenção para a possibilidade, felizmente baixa, mas real, de complicações graves que podem ocorrer após a simples exérese de um lipoma ou de outros nódulos benignos. Isso deve ser considerado e discutido entre o médico e a paciente, de forma que o risco e o benefício sejam bem estudados antes do ato cirúrgico, evitando que dúvidas e contestações possam ser levantadas após tal complicação.

\section{SUMMARY}

A case of postsurgical necrotizing fasciitis is presented. A 68year-old female patient was submitted to a lumpectomy for a big breast lipoma. After surgen there was an aggressive local infection, with extensive necrosis of the breast tissue, including the superficial and deep fasciae and also the skin over the breast. The gravity of the disease and the difficulties in its diagnosis due to the late skin necrosis are emphasized. Under such circunstances an early and aggressive approach is necessary.

KEY WORDS: Breast: Benign diseases. Surgical complication. Infection. Necrotizing fasciitis. 


\section{Referências bibliográficas}

1. Brook I, Frazier EH. Clinical and microbiological features of necrotizing fasciitis. J Clin Microbiol 1995; 33: 2382-7.

2. de Polavieja MG, Fernández R, Martínez C, Prieto F, García L, Bravo D. Infecciones necrosantes de partes blandas. Enferm Infecc Microbiol Clin 1996; 14: 16-20.

3. Freitas Jr R, Sousa JÁ, Moreira MAR. Drenagem de cavidade pós exérese de nódulos benignos da mama. Rev Col Bras Cir 1997; 24(suppl): 49.

4. Green RJ, Dafoe DC, Raffin TA. Necrotizing fasciitis. Chest 1996; 110: 219-29.

5. Law NW, Lamont PM, Johnson CD, Ellis H. Drainage or suture of the cavity after breast biopsy. Ann R Coll Surg Eng1 1990; 72: 11-3.

6. Velasco IGM, Valadez VP, Treviño JS, Gutierrez JS, Saldivar AT. Fascitis necrotizante postcesárea. Sinergismo bacteriano o infección de tejidos blandos? Ginecol Obstet Mex 1996; 64: 58-63. 